\title{
JÜRGEN HABERMAS: SOBRE A NECESSIDADE DE UMA FILOSOFIA PÓS- METAFÍSICA DA HISTÓRIA PARA SUBSIDIAR NORMATIVAMENTE A \\ PRÁXIS
}

\section{Dr. Marcos André De Barros'}

\begin{abstract}
RESUMO
O texto pretende mostrar como e porque o filósofo alemão Jurgen Habermas, apesar de ser um crítico da filosofia da história e autor de um projeto de destrancendentalização da filosofia, ainda reconhece a necessidade de uma concepção filosófica da história para oferecer suporte e estímulo à práxis éticopolítica, e para tanto constrói uma teoria da evolução como uma reconstrução do materialismo histórico enquanto uma teoria pós-metafísica (pretensamente empiricamente demonstrável) à altura de uma razão comunicativa emancipatória
\end{abstract}

Palavras-chave: Razão histórica; Pensamento pós-metafísico; Práxis emancipatória; J. Habermas; Teoria crítica.

\section{Introdução}

Os limites do discurso universalista e previsibilista das filosofias da história, a reconfiguração da razão para além do modelo instrumental como razão comunicativa e o lugar de uma teoria evolutivista no discurso histórico são os fundamentos nos quais se apóia a empreitada habermasiana de conceber filosoficamente, em termos pós-metafíciso, a história para fins práticos. E é exatamente isto que queremos tentar expor aqui.

\section{A desqualificação das filosofias da história}

Com a publicação de $A$ dialética do esclarecimento, de Theodor Adorno e deMax Horkheimer, argumentos claros são apresentados para a demonstração da tese deque a razão tornou-se mito, o acúmulo de conhecimento que se converte em força e técnica de controle e dominação da natureza, transformou-se ele mesmo em dominação do homem pelo homem. Não há, na direção em que a humanidade se encaminha, ponto de chegada nenhum ("plano da natureza" ou "astúcia da razão"), o único aperfeiçoamento é o da

\footnotetext{
${ }^{1}$ Doutor em Filosofia pela UFRJ, Professor Associado da UFRPE. E-mail: mabbarros@bol.com.br.
} 
capacidade de destruir a natureza e de transformar o ser humano em objeto ("reificação", rés do latim= coisa ). A racionalidade expressa na relação sujeitoobjeto converteu a relação homem-homem na relação homem-coisa cujo guia é o poder técnico.

Seguindo Max Weber na interpretação do processo histórico que tem seu ápice na modernidade, entendida como processo de racionalização (desencantamento, secularização, emprego da racionalidade meio-fim e autonomia das esferas culturais), os primeiros pensadores frankfurtianos, identificaram a razão com a "ação racional com relação a fins" (oposta à ação racional com relação a valores).

Com o argumento de que não há plano subjacente à história, o único papel deixado às teorias do sentido histórico foi o de ideologia (fantasia), ou seja, as classes no poder para efetivar seu domínio utilizaram-se de teorias desse tipo, que insinuavam poder prever o sentido (a direção) da história e seu significado. As filosofias da história eram universalizações do interesse de classe e não racionalidade histórica, todas elas (inclusive a liberal e a socialista)referem-se a um futuro que na verdade não podem conhecer e nem podem oferecer. Ao contrário, o que surgiu de suas apropriações foi sempre algo autoritário e totalitário (irracional).

Habermas, leitor atento de Max Weber - Estudos de sociologia da religião; de Horkheimer - filosofias burguesas da história; e de Adorno - Dialética negativa, recusa-se a construir mais uma proposta previsibilista e abstrata. Considerando os limites do exame empírico e apoiando-se em historiadores e cientistas sociais, tais como Ernst Gehler, Klaus Eder, Niklas Luhmann, G. Markus, Claus Offe, Jean Piaget e Laurence Kohlberg entre outros, propõe-se a abordar a questão de um lugar para a filosofia da história em sua relação com a historiografia. Três são as questões principais as quais Habermas (1990) se volta na obra Para a reconstrução do materialismo histórico: 1 . Os limites do discurso universalista em história; 2. Reconfiguração da razão para além do modelo instrumental; 3. O lugar de uma teoria evolutivista no discurso histórico.

\section{A questão do discurso histórico}

Quanto ao limite do discurso histórico universalista, Habermas entende que acrescente sociologização do discurso histórico o fez cada vez 
mais interessado pelo satores individuais e pelos grupos e que teorias do desenvolvimento unilinear não conseguem justificativas empíricas, o que faz com que em boa medida os modelos hegeliano, marxista e evolucionista das filosofias da história se tornem insustentáveis.

Habermas, porém, vê que há um outro campo no qual uma ideia de uma razão "universal"empírica histórica é aplicável. Este campo distinto do âmbito do chamado "paradigma da produção" em crise (e de sua "razão instrumental" voltada para a exploração e a manipulação), no qual uma razão ainda universal pode ser identificada, é o âmbito da interação, firmado pela comunicação voltada para o entendimento (consenso e valores) e articulado pela "razão comunicativa". O meio empírico que lastreia a comunicação dirigida para o entendimento é o "mundo da vida cotidiana", este por sua vez sustenta-se na comunicação espontânea e voltada para o entendimento, articulado por valores e normas.

Para dar conta desta concepção Habermas passou a trabalhar com um conceito ampliado de razão ("razão comunicativa"), que vai além do aspecto estratégico e instrumental. Esta conceituação da razão engloba de imediato o campo da prática (decisões, valoração e vontade) e seu aparelho medidor de evolução é a capacidade comunicativa da espécie humana. Portanto, (3) o âmbito para a aplicação de uma filosofia evolutivista da história é o da "formação discursiva da vontade" por meio da "argumentação prática". Assim sendo, a história universal não serviria propriamente ao interesse instrumental produtivista, mas ao âmbito reflexivo da condição humana que exige subsídios para as decisões que encaminham o homem para o futuro (HABERMAS, 1990, p. 111-209)

Mas, a pergunta persistente é: há ou não há condições para se falar de uma história universal em Habermas? A resposta é sim, e esta "história universal da espécie humana" assume uma dupla caracterização, por um lado, analisa a ampliação da capacidade de comunicação voltada para o entendimento e seu caráter inclusivo; e, por outro lado, identifica criticamente os instantes e os meios de repressão da comunicação livre de coação. Cabe, entretanto, destacar que a teoria de Habermas sobre a história, para muitos de contorno indefinido, não se trata de uma teoria ontológica (metafísica) da verdade histórica, mas de uma teoria epistemológica. 


\section{A história como exigência para uma práxis esclarecida}

A teoria de Habermas não é uma teoria do ser ou do sentido absoluto da história. A própria conceituação da razão de Habermas não permite falar em termos absolutos, o que a razão produz equivale a modelos que se expõem com pretensões de validade ou de verdade, ao exporem-se esses modelos ou teorias pretendem conter a verdade que aguarda dos seus examinadores a certificação. Sendo assim, o que a filosofia pós-metafísica de Habermas oferece é uma teoria da história que dê suporte à práxis, teoria na qual a "verdade" da história tem um sentido epistemológico que serve como modelo com pretensão de validade.

A história, portanto, para Habermas não se apresenta em termos ontológicos, mas em termos epistemológico e ético, pois ela será utilíssima como orientação à práxis que define os encaminhamentos da civilização. Uma teoria da história serve, principalmente, para que as questões práticas se reforcem em seus fundamentos epistemológicos como campo da vontade (decisão) racional e para que a prática não se reduza à técnica. Segundo Habermas, a técnica é insuficiente para oferecer um lastro para as decisões humanas quanto ao futuro da humanização do mundo, pois não é capaz de discernir a amplitude de seus efeitos sobre todos os concernidos.

Apesar de não-metafísico, por basear-se na linguagem como fundamento do conhecer e da razão, o modelo teórico da história apresentado por Habermas sustenta-se numa consistente base empírica: trata-se da homologia entre o desenvolvimento dos indivíduos (ontogênese) e o desenvolvimento da espécie (filogênese). A idéia de Habermas é apresentar os "processos de aprendizagem" responsáveis pela evolução individual (modelo de Piaget e Kohlberg) como homologamente existentes na espécie.

Desse modo a história é a história dos processos de aprendizagem da espécie humana em direção à sua emancipação (autonomia políticomoral) pelo esclarecimento. Quanto aos aspectos que indicam a ocorrência de tais desenvolvimentos, Habermas não aceita que já os tenhamos identificado todos em nossa geração, estes mesmos aspectos que se apresentam na atualidade podem, em um futuro, ter outros acrescidos a si, e mesmo os eu status pode ser revisto. Há, todavia, uma forte motivação reflexiva para que se pense evolutivamente: auxiliar a práxis normativa cotidiana. 
Portanto, A história universalista de Habermas se funda numa homologia entre indivíduo e sociedade, mais especificamente entre a formação da identidade do Eu individual e a identidade coletiva da sociedade, que assegura continuidade e reconhecibilidade. Para este filósofo a identidade na modernidade não é ofertada pela religião, nem por uma tradição, e sim por uma "visão de mundo" bastante ampla e flexível, mas muito bem distinta de outras visões de mundo (anteriores).

Para construir sua homologia Habermas, na esteira de Piaget, propõe que se investigue nas sociedades complexas a existência de uma identidade, que, segundo ele, só pode ser uma "identidade reflexiva". Se no indivíduo seu desenvolvimento psicológico em termos de consciência moral ou competência interativa indica os estágios ou níveis pré-convencional (comportamento baseado na punição e na recompensa), convencional (comportamento baseado na concordância interpessoal e orientação "lei e ordem”); e pós-convencional (comportamento autônomo e fundado em princípios morais universais), na história das sociedades Habermas estrutura sua análise destacando elementos morais presentes nos índices de redução de "conflituosidade" e na "solução de conflitos". Afiguram-se assim as seguintes sociedades, conforme a disponibilidade em cada uma de condições formais para práticas integradoras e racionalizadoras comunicativas (dirigidas ao entendimento e à construção de normas baseada em princípios universais): Sociedades neolíticas preponderantemente pré-convencionais; Primeiras grandes civilizações e Civilizações desenvolvidas - majoritariamente convencionais; Época moderna preponderantemente pós-convencional. A disponibilização das condições formais, todavia, não quer indicar uma larga prática.

Para melhor esclarecer esta complexa concepção da história vamos destacar o que Habermas $(1990,98)$ considera o fio condutor do processo de autoconstrução autônoma (humanização) das sociedades:

Uma identidade coletiva [...] sob a forma reflexiva, ou seja, no sentido de ser fundada na consciência de ter oportunidades iguais e gerais para tomar parte nos processos de comunicação, nos quais a formação da identidade tem lugar como processo contínuo de aprendizagem.

Mais especificamente, Habermas (1990 b, 11-29), compreende a modernidade como um processo racionalizador (inacabado), cuja práxis social pode abranger ao mesmo tempo o desenvolvimento de regras técnico- 
utilitaristas no âmbito do processo de produção e de apropriação (modernidade social) integradas a um processo de interação normativamente voltada para o entendimento (modernidade cultural). Resulta desta combinação a emergência de uma "nova identidade" de uma "sociedade mundial" (pós-nacional) que está apenas "no nascedouro": uma sociedade da comunicação, do reconhecimento e da participação autônoma, cujo processo de socialização se volta para a auto-atribuição social de tarefas plenificadoras, direcionadas à construção de um futuro onde se projetam formas de vida plenamente autônomas marcadas por uma identidade fundada na

[...] consciência de (dever garantir) oportunidades iguais e gerais para a participação nos processos de aprendizagem criadores de normas e de valores (como) o fundamento de uma nova identidade, que não deve ser mera projeção (HABERMAS, 1990, 101).

Desta forma, Habermas afirma não estarem as teses do materialismo histórico totalmente destituídas de sentido e propõe sua reconstrução com base na razão comunicativa. A modernidade, nesta concepção, com sua autocompreensão voltada para o futuro, é livrada de formas opressoras que mantém o futuro preso ao presente pelo esgotamento das energias utópicas na sociedade do trabalho. Habermas pretende retirá-la da ordem do sempre igual a partir de sua utopia comunicativa que funciona como "ideia regulativa" e projeção prática de horizontes humanizadores (HABERMAS, 1990,12-46 e HABERMAS, 2000).

Os problemas da concepção habermasiana da história são muitos, por tratar-sede um pensamento não metafísico, mais próximo do conhecimento científico, porém que pretende integrar o campo moral ao do desenvolvimento das forças de produção (interesses econômicos) e de organização do poder (administração e política). Pensar o sentido da práxis humana a partir dos pressupostos da existência de uma moral universalista implica integrar campos estruturalmente distintos e atribuir ao âmbito da decisão prática uma autonomia em relação á técnica, o que encontra muita resistência por parta dos interesses econômicos e políticos. Mesmo não considerando um determinismo natural, nem espiritual, Habermas finda propondo um sentido para a história que tem na modernidade o alcance crítico das condições para uma vida social que garanta o direito universal à comunicação, o lugar da autonomia como ação decisória e o desenvolvimento universal na forma de processos de 
aprendizagem criadores de normas e valores (Cf. HABERMAS, 1990b, 275$350)$.

A história enquanto passado mostra-se a Habermas como o palco de um amplo percurso da aprendizagem da espécie humana, cujos avanços são bem perceptíveis na construção de ordens do direito, da democracia e dos meios de acesso à cultura e ao incremento técnico da produção. Neste mesmo palco, todavia, encontra-se um roteiro de repressão, de bloqueio do diálogo e das oportunidades de acesso ao conhecimento e ao poder, que Habermas entende como "história negativa". Seu intuito, entretanto, é poder contribuir para uma emancipação da história humana desse ciclo de opressão e direcionála para sua sempre maior emancipação, ainda que não se saiba plenamente de antemão qual seja este ponto final.

\section{Conclusão}

A conclusão a que chegamos em nosso percurso é a de que reconhecimento e justiça são os grande ancoradouros de uma filosofia da história com pretensões de ser empiricamente demonstrável segundo Habermas, e que esta é a única forma possível e aceitável para uma filosofia da história, a qual, por isso mesmo, assume uma forma pós-metafísica. A necessidade de uma concepção da história que se mostra inafastável, mesmo na vigência de uma devastadora crise das filosofias absolutistas ou metafísicas da história, demonstra-se como um imperativo da práxis ao pensamento, no instante mesmo em que a práxis exige para si uma orientação normativoracional. É, portanto, a partir de um modelo frágil de razão (pós-metafísico, ou seja, falibilista e discutível) que se pode, sem excessos contraditórios, continuar a se pensar em um sentido da história para atender as demandas da práxis humana. Esta fragilidade se mostra, todavia, mais robusta e necessária do que a pseudo-onipotência metafísica ou do que o ceticismo absoluto que não parece oferecer nenhum parâmetro aglutinador e abandona os seres humanos a mercê do agitado e disforme movimento das relações de poder. Neste caso, identificamos Jürgen Habermas como o exitoso autor de uma reflexão sobre a história fundamentalmente voltada para um suporte à práxis. Sua concepção é evolutivista por basear-se no modelo de pesquisa do desenvolvimento psicológico do indivíduo de Piaget e Kholberg o qual ele vê em homologia 
com o desenvolvimento da espécie; em cujo desenvolvimento os processos de aprendizagem são estruturais e por isto a história é interpretada(epistemologicamente e não ontologicamente) como a história dos processos de aprendizagem da espécie humana rumo ao reconhecimento e à justiça.

\section{Referências}

BARROS, Marcos André de. Democracia e "medium" do direito em J. Habermas. Revista Perspectiva Filosófica. v. I, ano 8, p. 62-72, 2005.

HABERMAS, Jürgen. Para a reconstrução do materialismo histórico. 2. ed. Trad. de Carlos Nelson Coutinho. São Paulo: Brasiliense, 1990a.

.O discurso filosófico da modernidade. Trad. de Ana Maria Bernardo e outros. Lisboa: Publicações Dom Quixote, 1990b.

Era de transição: ensaios sobre o nosso tempo. Trad. de Flávio Beno Siebeneischler Rio de Janeiro: Tempo Brasileiro, 2000.

SIEBENEISCHLER, F. B. Jürgen Habermas: razão comunicativa e emancipação. Rio de Janeiro: Tempo Brasileiro, 1989. 